\title{
The Effect of Refrigerated and Frozen Storage on Butter Flavor and Texture
}

\author{
A. J. Krause, ${ }^{*}$ R. E. Miracle, ${ }^{*}$ T. H. Sanders, $\dagger$ L. L. Dean, $\dagger$ and M. A. Drake ${ }^{\star 1}$ \\ *Department of Food Science, Southeast Dairy Research Center, North Carolina State University, Raleigh 27695 \\ †Market Quality and Handling Research Unit, USDA, Agricultural Research Service, Raleigh, NC 27695
}

\begin{abstract}
Butter is often stored for extended periods of time; therefore, it is important for manufacturers to know the refrigerated and frozen shelf life. The objectives of this study were to characterize the effect of refrigerated and frozen storage on the sensory and physical characteristics of butter. Fresh butter was obtained on 2 occasions from 2 facilities in 113-g sticks and 4-kg bulk blocks (2 facilities, 2 package forms). Butters were placed into both frozen $\left(-20^{\circ} \mathrm{C}\right)$ and refrigerated storage $\left(5^{\circ} \mathrm{C}\right)$. Frozen butters were sampled after $0,6,12,15$, and $24 \mathrm{mo}$; refrigerated butters were sampled after 0 , $3,6,9,12,15$, and 18 mo. Every 3 mo, oxidative stability index (OSI) and descriptive sensory analysis (texture, flavor, and color) were conducted. Every 6 mo, peroxide value (PV), free fatty acid value (FFV), fatty acid profiling, vane, instrumental color, and oil turbidity were examined. A mixed-model ANOVA was conducted to characterize the effects of storage time, temperature, and package type. Storage time, temperature, and package type affected butter flavor, OSI, PV, and FFV. Refrigerated butter quarters exhibited refrigerator/stale off-flavors concurrent with increased levels of oxidation (lower oxidative stability and higher PV and FFV) within 6 mo of refrigerated storage, and similar trends were observed for refrigerated bulk butter after 9 mo. Off-flavors were not evident in frozen butters until 12 or 18 mo for quarters and bulk butters, respectively. Off-flavors in frozen butters were not correlated with instrumental oxidation measurements. Because butter is such a desirable fat source in terms of flavor and textural properties, it is important that manufacturers understand how long their product can be stored before negative attributes develop.
\end{abstract}

Key words: butter, storage, butter quality, oxidative stability

Received September 24, 2007.

Accepted November 8, 2007.

${ }^{1}$ Corresponding author: maryanne_drake@ncsu.edu

\section{INTRODUCTION}

Dairy manufacturers produce large amounts of butter in the winter months. It is often necessary to store this butter for extended periods until there is a demand for it. During refrigerated or frozen storage, degradation of quality may occur and this is an important issue when companies develop specification sheets for butter suppliers or for butter suppliers to design storage regimens. Butter is commonly stored for extended periods in blocks $(25 \mathrm{~kg}$ ) that are subsequently reworked into quarter-pound sticks. However, retail packages (sticks or quarters as they are referred to by industry) are also often stored for extended periods.

Previous studies have been conducted to examine the effect of storage time on butter flavor. Emmons et al. (1986) examined the effect of different wrapping types on 1-lb. butter prints stored at $-18^{\circ} \mathrm{C}$ and found no deterioration over a 12-mo period. Butter stored for 14 wk at $5^{\circ} \mathrm{C}$ remained high in quality according to graders, but some slight changes in flavor were observed for some packaging types. Butter flavor was analyzed by grading so statistical analysis of results, relative intensities, and the exact nature of the flavor degradation were not characterized. Jebson et al. (1974) examined storage of 25-kg blocks of butter packaged in parchment paper inside a fiberboard box at $-18,-10,-4$, and $4^{\circ} \mathrm{C}$ for 8 mo. Grading and peroxide value (PV) were used to evaluate butter quality. The coldest storage temperature $\left(-18^{\circ} \mathrm{C}\right)$ did not yield significantly higher quality butter than storage at $-10^{\circ} \mathrm{C}$ over the $8-\mathrm{mo}$ period. From these results, it was concluded that $-10^{\circ} \mathrm{C}$ was the best storage temperature in terms of convenience and butter quality.

A variety of studies have examined butter wrapping materials. Parchment paper was reported as a source of prooxidants (copper, iron, and sulfuric acid) by Pont (1961). Downey and Murphy (1968) found that off-flavors in butter were related to the amount of light transmitted through the wrapper. MacBean (1974) compared cellophanes, low- and high-density polyethylenes, and polypropylenes with vegetable parchment for butter storage. Samples were stored under accelerated condi- 
tions $\left(62 \mathrm{~d}\right.$ at $5^{\circ} \mathrm{C}$, with three 4 -d periods in which the butter was stored at ambient temperature) to simulate $1 \mathrm{yr}$ of frozen storage. High-density polyethylene was most similar to vegetable parchment in terms of quality maintenance although it was concluded that cost would be prohibitive to its usage. Tomlinson and Dixon (1977) confirmed that polyethylene films provided the best protection against surface oxidation and provided the best freeze-thaw stability. Recently, Lozano et al. (2007) demonstrated that foil packaging significantly improved refrigerated and frozen flavor stability of butter quarters compared with parchment paper.

Few recent studies have evaluated the sensory perception of butter flavor and texture. Several studies have examined the relationship between sensory perception of texture (firmness and spreadability) and the relationship to instrumental measurements including probe penetration, uniaxial compression, and yield stress (Kawanari et al., 1981; Mortensen and Danmark, 1982; Fearon and Johnston, 1989; Rohm and Ulberth, 1989; Rousseau and Marangoni, 1999). Krause et al. (2007) recently conducted preference mapping of butter to identify drivers of liking. Key butter features to consumers were desirable flavor and natural image; negative aspects included price and cholesterol.

To our knowledge, recent studies have not addressed butter storage stability. Further, the stability of bulk and stick butter have not been compared. Our objective was to evaluate the flavor and texture stability of bulk and stick butter across frozen $\left(-20^{\circ} \mathrm{C}\right)$ and refrigerated $\left(5^{\circ} \mathrm{C}\right)$ storage. Descriptive sensory analysis, which has not been widely applied to butter flavor, was used to monitor flavor and texture, and instrumental methods were used to evaluate chemical and texture changes.

\section{MATERIALS AND METHODS}

\section{Production and Sampling}

Two butter production facilities (in California) were sampled on 2 different days. On each of the $2 \mathrm{~d}$, bulk butter (25-kg blocks split into 4-kg blocks and packaged individually in polyethylene bags, Grade AA, salted; $122.5 \mathrm{~kg}$ from each facility on each day) and stick butter (113-g wax paper-wrapped sticks, in paperboard packages of 4, Grade AA, salted, $49 \mathrm{~kg}$ each day from each facility) were obtained by overnight shipment on ice packs. Bulk butter was evaluated as subdivided $4-\mathrm{kg}$ blocks rather than $25-\mathrm{kg}$ blocks to minimize waste at each timepoint and to minimize the initial volume of bulk butter required. A total of $735 \mathrm{~kg}$ of butter was received at the beginning of February 2005 (245 kg as sticks and $490 \mathrm{~kg}$ as bulk blocks). Moisture, fat, and salt content were analyzed upon receipt by the modified Kohman method (Bradley et al., 1993). Products were assigned to refrigerated $\left(5.0 \pm 1.0^{\circ} \mathrm{C}\right)$ and frozen $(-20.0$ $\pm 1.0^{\circ} \mathrm{C}$ ) storage conditions and stored in the dark.

At 3-mo intervals, samples were taken from refrigerated storage $(0,3,6,9,15$, and $18 \mathrm{mo} ; 21$ and $24 \mathrm{mo}$ for sensory analysis only) and every 6 mo, samples were taken from frozen storage $(0,6,12,15,18,21$, and 24 mo). At the 3-mo time points, oxidative stability index (OSI) was determined and sensory analysis was performed. At the 6-mo time points, all tests were performed [color, PV, OSI, free fatty acid value (FFV), vane, and sensory analysis]. Fatty acid profiling was conducted initially and after $6 \mathrm{mo}$ of storage. Tests were performed within 2 wk of the sampling date. The outer $1 \mathrm{~cm}$ of bulk samples and the outer $2 \mathrm{~mm}$ of butter quarters were trimmed before evaluation in an effort to obtain representative samples for all physical and sensory tests.

\section{Fatty Acid Profiling}

Fatty acid methyl esters were prepared with methods adapted from Bannon et al. (1982). Each sample was analyzed in triplicate. One drop of oil from melted butter (20 to $30 \mathrm{mg}$ ) was weighed into a screw-capped tube, and $1 \mathrm{~mL}$ of $0.5 \mathrm{M}$ methanolic potassium hydroxide (Fisher Scientific, Fairlawn, NJ) was added. The tube was capped and placed into an $80^{\circ} \mathrm{C}$ oven for $10 \mathrm{~min}$. After the tube was cooled, $1 \mathrm{~mL}$ of boron trifluoride (Sigma-Aldrich, St. Louis, MO) was added. The capped tube was heated for $5 \mathrm{~min}$ in an $80^{\circ} \mathrm{C}$ water bath. After the tube was cooled slightly, $1 \mathrm{~mL}$ of deionized water and $1 \mathrm{~mL}$ of hexane were added (Optima grade, Fisher Scientific). The tube was vortexed for $30 \mathrm{~s}$ and the contents were allowed to settle. The top hexane layer was removed and placed into a tube containing $1 \mathrm{~g}$ of sodium sulfate (Sigma-Aldrich) to remove any water present. The hexane phase containing the fatty acid methyl esters was then transferred to a vial for GC analysis.

A PerkinElmer Autosampler XL (PerkinElmer, Boston, MA) was used with a Restek RT-2560 column (Restek, Bellefonte, PA) equipped with a flame-ionization detector (detector temperature $220^{\circ} \mathrm{C}$, injector temperature $220^{\circ} \mathrm{C}$ ). The initial temperature was $100^{\circ} \mathrm{C}$, which was held for $2 \mathrm{~min}$, and then the temperature was increased at $3^{\circ} \mathrm{C} / \mathrm{min}$ up to $250^{\circ} \mathrm{C}$, which was held for 2 min. The total run time was $54 \mathrm{~min}$. Helium at $0.4 \mathrm{~mL} /$ min was used for the carrier gas, and hexane was used as a blank. The following standards were used: GLC21A (Nu-Chek Prep Inc., Elysian, MN), Kel-Fim FAME7 Standard (Matreya, Pleasant Gap, PA), and Restek \#35078 (Restek). To confirm that butter fatty acid composition did not change appreciably with season, freshly produced butter quarters were also collected from each 
Table 1. Sensory language used for the descriptive sensory analysis of butter ${ }^{1}$

\begin{tabular}{|c|c|c|}
\hline Term & Definition & Reference \\
\hline Diacetyl/cultured ${ }^{2}$ & $\begin{array}{l}\text { Sweet aromatic characteristic of cultured dairy } \\
\text { products, of which diacetyl is a primary source }\end{array}$ & Diacetyl, $20 \mathrm{mg} / \mathrm{kg}$ \\
\hline Milkfat/lactone $^{2}$ & $\begin{array}{l}\text { Aromatic characteristic of milkfat, lactones, and } \\
\text { coconut }\end{array}$ & Heavy cream \\
\hline Cooked/nutty & $\begin{array}{l}\text { Aromatic associated with cooked milk } \\
\text { and canned corn }\end{array}$ & $1 \%$ fat milk heated in a microwave for $8 \mathrm{~min}$ \\
\hline Refrigerator/stale & $\begin{array}{l}\text { Stale aromatic characteristic of refrigerator } \\
\text { with old food left in it }\end{array}$ & $\begin{array}{l}\text { Butter quarters (sticks) stored in a refrigerator } \\
\text { for } 18 \text { mo }\end{array}$ \\
\hline Salty $^{3}$ & Taste elicited by $\mathrm{NaCl}$ & $\begin{array}{l}\text { Sodium chloride solutions; } \\
0.5 \%(5), 0.7 \%(8), 0.9 \%(11.5)\end{array}$ \\
\hline Yellow color intensity ${ }^{4}$ & Intensity of yellow color & Yellow color scale $3 \mathrm{~A}$ \\
\hline Spreadability & $\begin{array}{l}\text { Force necessary to spread three strokes, } \\
\text { backward, forward, backward on } \\
\text { unsalted saltine cracker }(1 / 2 \text { " tip of the } \\
\text { knife) } 0=\text { not spreadable, } 10=\text { very spreadable }\end{array}$ & $\begin{array}{l}\text { Land O'Lakes spreadable butter (9) } \\
\text { Crisco vegetable oil sticks (8.5) } \\
\text { Challenge butter (5); } \\
\text { tempered for } 1.5 \mathrm{~h} \text { at } 19^{\circ} \mathrm{C}\end{array}$ \\
\hline
\end{tabular}

\footnotetext{
${ }^{1}$ Language adapted from Krause et al. (2007).

${ }^{2}$ Reference taken from Drake et al. (2001).

${ }^{3}$ Reference taken from Meilgaard et al. (1999.

${ }^{4}$ Reference taken from Kornerup and Wanscher (1978).
}

California facility in August, and fatty acid profiling was conducted.

\section{Descriptive Sensory Analysis}

Color, flavor, and texture attributes (Table 1) were evaluated across storage. Eight panelists ( 7 females, 1 male) were selected based on availability and previous experience ( $>75 \mathrm{~h}$ each) with descriptive sensory analysis of dairy products using the Spectrum method (Meilgaard et al., 1999). Panelists received an additional 25 $\mathrm{h}$ of training to focus on identification and scaling of butter flavor and texture attributes. During training, panelists discussed and evaluated an array of commercial butters. The Spectrum universal scale was used to scale the intensity of flavor attributes (Meilgaard et al., 1999) using the language described by Krause et al. (2007; Table 1). Color intensity/hue was evaluated using the scale applied by Krause et al. (2007; Table 1). A 10-point product-specific scale was used to score butter spreadability and firmness (Table 1). Before testing, an ANOVA of panel and panelist performance on selected butters was used to determine that panelists could consistently identify and scale butter color, flavor, and texture attributes. Two weeks before each testing timepoint, panelists received an additional $3 \mathrm{~h}$ of refresher training and calibration, and panel and panelist performance on butter sensory attributes were once again confirmed to be consistent.

For sensory analysis, samples $(7 \mathrm{~g})$ were prepared with the overhead lights turned off to prevent light- induced flavor changes, and placed in 58-mL soufflé cups (Sweetheart Cup Company Inc., Owings, MD) and stored at $5^{\circ} \mathrm{C}$ in the dark. One and a half hours before the panel session, butters were tempered to $19^{\circ} \mathrm{C}$. This temperature was chosen for sensory analysis because panel training sessions indicated that panelists could best identify subtle variations in butter flavor at this temperature and this was also the temperature used for vane texture analysis. Panelists individually evaluated samples under white light using paper ballots or computerized data entry (Compusense 5 v4.6, Compusense, Guelph, Canada) in individual booths in a positive air pressure room dedicated to sensory analysis. Each treatment was evaluated in duplicate by each panelist at each timepoint. For flavor evaluations, 2 warm-up samples (butters that had previously been profiled by the panel) were provided with their consensus flavor profiles along with salty taste solution references (Table 1). For texture evaluation, panelists were provided with firmness and spreadability references (Table 1). To evaluate color, panelists were instructed to compare the sample to a provided color scale. Flavor/color and texture were evaluated in separate sessions. Panelists were given deionized water and unsalted saltine crackers between samples for palate cleansing. To prevent temporal cues from unduly influencing panelists, at each timepoint, a fresh butter (from one of the California facilities, less than $72 \mathrm{~h}$ old) was included in the samples evaluated. 


\section{Solid Butter Color}

Two 10-g samples were taken and pressed into separate $60-\times 15-\mathrm{mm}$ polystyrene Petri dishes (Falcon 1007 , Becton Dickinson, Franklin Lakes, NJ). Five replications of $L^{*}, a^{*}$, and $b^{*}$ were taken at random places on each Petri dish with a Minolta Colorimeter (Konica Minolta, Tokyo, Japan). The samples were evaluated at $19^{\circ} \mathrm{C}$.

\section{Centrifuged Oil Color}

Two samples ( $45 \mathrm{~g}$ each) were placed into $50-\mathrm{mL}$ conical centrifuge tubes (Falcon, Becton Dickinson). The tubes were wrapped in foil and placed in a $50^{\circ} \mathrm{C}$ water bath for $8 \mathrm{~min}$ to melt the butter followed by centrifugation (model 225, Fisher Scientific) for $12 \mathrm{~min}$ at 3,400 $\times g$ at $50^{\circ} \mathrm{C}$. The top oil layer was pipetted off and combined. An aliquot of oil (5 g) was placed into each of 2 Petri dishes $(60 \mathrm{~mm} \times 15 \mathrm{~mm}$ polystyrene). Five replications of $L^{*}, a^{*}$, and $b^{*}$ were taken at random places on each Petri dish with a Minolta Colorimeter (Konica Minolata). The oil samples were evaluated at $50^{\circ} \mathrm{C}$.

\section{OSI}

Two samples (45 g each) of butter were placed into 50 $\mathrm{mL}$ conical centrifuge tubes (Falcon, Becton Dickinson) and prepared as described for oil color measurements. An aliquot of oil ( $5 \mathrm{~g}$ ) was placed into three $100-\mathrm{mL}$ glass disposable OSI tubes (Omnion Inc., Rockland, MA). The OSI tubes were placed in the oxidative stability instrument (Omnion Inc.) and a conductivity meter was inserted. Air at $0.05 \mathrm{~mL} / \mathrm{min}$ was connected. The temperature was set at $110^{\circ} \mathrm{C}$. Testing was conducted in duplicate until a peak in conductivity was recorded by the instrument.

\section{PV}

Peroxide value was modified from AOCS Official Method 965.33 (Chen et al., 2004). Briefly, 2 samples (45 g each) of butter were placed into $50-\mathrm{mL}$ conical centrifuge tubes (Falcon, Becton Dickinson), wrapped in foil, and placed in a $50^{\circ} \mathrm{C}$ water bath for $8 \mathrm{~min}$. Following this, the samples were centrifuged (model 225 , Fisher Scientific) for $12 \mathrm{~min}$ at $3,400 \times g$ at $50^{\circ} \mathrm{C}$. The top oil layers were pipetted off and combined. An aliquot of oil $(5 \mathrm{~g})$ was placed into each of three 250$\mathrm{mL}$ Erlenmeyer flasks. Thirty milliliters of 3:2 acetic acid:chloroform (both Fisher Scientific) and $0.5 \mathrm{~mL}$ of saturated potassium iodide (Fisher Scientific) solution was added. After $1 \mathrm{~min}, 30 \mathrm{~mL}$ of deionized water was added. The flasks were titrated with $0.01 M$ sodium thiosulfate (Fisher Scientific) until disappearance of yellow color. Starch solution (1\%, J.T. Baker Chemical Co., Phillipsburg, NJ) was added to the flask $(0.5 \mathrm{~mL})$. The titration was continued until the blue color disappeared. The PV ( $\mathrm{mEq}$ of peroxide/kg of oil) was calculated as: (mL of sodium thiosulfate) $\times$ (molarity of sodium thiosulfate $) \times 1,000 /($ sample weight in $\mathrm{g})$.

\section{FFV}

Two samples ( $45 \mathrm{~g}$ each) of butter were placed into 50 $\mathrm{mL}$ conical centrifuge tubes (Falcon, Becton Dickinson) and prepared as described for oil color measurements. An aliquot of oil $(7.05 \mathrm{~g})$ was placed into three $250-\mathrm{mL}$ flasks. Fifty milliliters of neutralized isopropyl alcohol (99\% neturalized with $\mathrm{NaOH}$ to a faint pink color) and $1 \mathrm{~mL}$ of indicator [phenolphthalein 1\% (wt/vol) in $95 \%$ ethanol; Fisher Scientific] were added to the flask. The solution was titrated with $0.025 \mathrm{~N} \mathrm{NaOH}$ until a faint pink color was maintained for $1 \mathrm{~min}$. Free fatty acid value was calculated as follows: ( $\mathrm{mL}$ of $\mathrm{NaOH} \times$ normality of $\mathrm{NaOH} \times 40) / \mathrm{g}$ of oil, as measured in milligrams of $\mathrm{NaOH} / \mathrm{gram}$ of oil.

\section{Vane Rheometry}

The vane test was used for instrumental texture analysis. The vane test has been used successfully to evaluate products such as ice cream (Briggs et al., 1996), peanut butter, margarine spreads, sour cream, whipped topping (Daubert et al., 1998), and cream cheese (Breidinger and Steffe, 2001). The yield stress was calculated from the amount of torque necessary to rotate the vane through the butter. The apparent yield strain was calculated from the time of maximum yield stress. A Haake VT550 rheometer (Thermo Electron Corporation, Waltham, MA) was used. Butter samples were tempered in a $19^{\circ} \mathrm{C}$ incubator until they reached an internal temperature of $19^{\circ} \mathrm{C}(\sim 1 \mathrm{~h})$. Preliminary experiments with temperature probes were conducted to confirm the butter internal temperature of $19^{\circ} \mathrm{C}$. Samples were forced into a metal box $[3.5 \mathrm{~cm} \times 3.5 \mathrm{~cm} \times 7.5 \mathrm{~cm}$ (inside diameter) mounted on a $17.6-\times 4-\mathrm{cm}$ metal plate]. The metal box was clamped to a stand. When the internal temperature of the butter reached $19^{\circ} \mathrm{C}$, the vane was inserted $(1.0 \mathrm{~cm}$ in diameter, $2.5 \mathrm{~cm}$ in height); the instrument rotated at $0.02 \mathrm{rpm}$. Yield stress was calculated as follows (Dzuy and Boger, 1983): $\sigma=2 \mathrm{M}_{0} / \pi \mathrm{d}^{3}$ $(\mathrm{h} / \mathrm{d}+1 / 6)^{-1}$, where $\sigma=$ yield stress in pascals; $\mathrm{M}_{0}=$ maximum torque in newton meters; $\mathrm{d}=$ diameter of the vane in meters $(0.01 \mathrm{~m})$; and $\mathrm{h}=$ height of the inserted vane in meters $(0.025 \mathrm{~m})$.

The strain exhibited at the yield stress, termed the apparent yield strain, was calculated as follows (Dau- 
bert et al., 1998; Breidinger and Steffe, 2001): $\gamma_{0}=\mathrm{t} \Omega /$ $2 \pi$, where $\gamma_{0}=$ apparent yield strain in radians; $\mathrm{t}=$ time to reach yield stress in seconds; and $\Omega=$ rotational speed of vane in revolutions/second.

\section{Statistical Analysis}

Statistical analysis was conducted to determine the impact of package (bulk, stick), storage temperature, and storage time on butter attributes. The Proc Mixed of SAS (version 9.1, SAS Institute Inc., Cary, NC) was used to evaluate main effects and interactions between packaging and temperature variables with storage time. Replications (production facility and day) were considered random effects. The SAS slice command was used to clarify effects in the event of significant secondary interactions. Fisher's least significant difference (LSD) was used for means separation.

\section{RESULTS AND DISCUSSION}

\section{Proximate Analysis and Fatty Acid Profiles}

Stick butter averaged (mean \pm standard deviation) $80.6 \pm 0.15 \%$ fat, and bulk butter was $80.4 \pm 0.04 \%$ fat. Bulk butter contained slightly more salt ( $16.4 \pm 0.06 \%$ moisture and $1.8 \pm 0.1 \%$ salt, respectively) than did butter quarters $(16.3 \pm 0.13 \%$ moisture and $1.6 \pm 0.1 \%$ salt, respectively; $P<0.05$ ). Comparison of the levels of saturated, monounsaturated, and polyunsaturated fatty acids in the butters was conducted upon receipt and on both refrigerated and frozen samples after 6 mo. Butter produced in the summer months (August) was also collected fresh from the same facilities to determine if the fatty acid content differed with season. Statistical analysis revealed no significant differences in fatty acid profiles between the fresh butter and 6-mo refrigerated and frozen butters. Additionally, there were no significant differences between the butter produced in the summer and that collected in February, which was used for the storage study (results not shown).

\section{Descriptive Sensory Analysis}

Butters were initially characterized by cooked/nutty, milkfat, and salty taste (Table 2). Previous work has demonstrated that these flavors are typical of freshly churned salted butter in the United States (Krause et al., 2007). Salty taste was consistent over time and storage conditions $(P>0.05)$. Bulk butter had a greater salt intensity $(10.08 \pm 0.15)$ than butter sticks $(9.10 \pm$ $0.06, \mathrm{LSD}=0.2, P<0.05$ ), consistent with its greater salt content. Color and firmness had no significant interactions, were not different between bulk or stick but- ter, and did not change with storage time or storage conditions (color intensity $=1.86 \pm 0.02$; firmness $=5.62$ $\pm 0.35 ; P>0.05)$.

A decline in cooked/nutty flavor (a flavor that is prevalent in freshly churned butter; Krause et al., 2007) occurred over time $(P<0.05$; Table 2$)$. Flavor changes with storage time were different for different package types and storage temperatures $(P<0.05)$. At refrigeration temperature, a significant decrease $(P<0.05)$ in cooked/nutty flavor occurred with storage time across all packaging types. This decrease was more rapid in the wax paper-wrapped sticks compared with bulk butter. A decrease in this fresh flavor was observed after 3 mo of refrigeration in both bulk and stick butter. A much slower reduction was observed in the frozen product, but the same trend in packaging was noted (wax paper-wrapped sticks had the most rapid decline, and bulk butter had the slowest decline). Intensities of cooked/nutty flavor detected after 12 mo in the frozen product were not significantly different than intensities observed at $3 \mathrm{mo}$ in the refrigerated product.

Milkfat flavor intensity (another flavor prevalent in freshly churned butter) changed over time and was different between storage temperatures $(P<0.05)$, but not package types $(P>0.05$, Table 2$)$. A decline in milkfat flavor was detected in both refrigerated and frozen samples, but similar to cooked/nutty flavor, the decline occurred more rapidly in refrigerated samples.

Development of a refrigerator/stale flavor was observed in butters over storage time. Differences in the development of this storage flavor between package and storage temperature were also observed $(P<0.05$, Table 2 ). Refrigerator/stale flavor developed more quickly in refrigerated butter compared with frozen butter. After $6 \mathrm{mo}$, refrigerator/stale flavor was above the sensory threshold in refrigerated wax paper-wrapped sticks, and at 12 mo it was detected in refrigerated bulk butter. Bulk butter developed refrigerator/stale flavor more slowly than did stick butter. At frozen storage temperatures, refrigerator/stale flavor was detected at 12 mo in wax-paper-wrapped sticks and was not detected until 21 mo in bulk butters. Panelists were trained to identify and score specific lipid degradation flavors in butter (painty/oxidized and free fatty acid) that were occasionally encountered when a wide array of commercial butters were evaluated (Krause et al., 2007). However, these flavors were not reported in the current study. Some changes in texture were observed by the trained panel. A decrease in the ease of spreadability was observed over time by the trained panel in both refrigerated and frozen butter $(P<0.05$, Table 3$)$. Differences were not observed between bulk and stick butters.

To our knowledge, our study is the first to use a trained panel to evaluate texture changes in butter over 
Table 2. Trained panel perception of flavor intensities that changed with time, packaging type, and storage temperature $\mathrm{e}^{1,2}$

\begin{tabular}{|c|c|c|c|c|c|c|c|c|c|c|}
\hline \multirow[b]{2}{*}{ Temperature } & \multirow[b]{2}{*}{ Packaging } & \multicolumn{9}{|c|}{ Time (mo) } \\
\hline & & 0 & 3 & 6 & 9 & 12 & 15 & 18 & 21 & 24 \\
\hline \multicolumn{11}{|c|}{ Cooked/nutty flavor $(\mathrm{LSD}=0.2)$} \\
\hline \multirow[t]{2}{*}{ Refrigerated } & Bulk & 3.7 & 3.2 & 2.3 & 2.4 & 1.9 & 1.7 & 1.1 & 1.1 & 1.2 \\
\hline & Sticks & 3.9 & 2.7 & 2.0 & 2.1 & 1.4 & 1.6 & 1.0 & - & - \\
\hline \multirow[t]{2}{*}{ Frozen } & Bulk & - & - & 3.1 & - & 3.3 & 2.8 & 2.6 & 2.7 & 2.0 \\
\hline & Sticks & - & - & 3.0 & - & 2.6 & 2.7 & 2.6 & 2.5 & 2.0 \\
\hline \multicolumn{11}{|c|}{ Milkfat flavor $(\mathrm{LSD}=0.2)$} \\
\hline Refrigerated & $\mathrm{NS}^{3}$ & 3.0 & 3.1 & 2.6 & 2.6 & 2.5 & 2.0 & 1.6 & $2.4^{4}$ & $2.0^{4}$ \\
\hline Frozen & NS & - & - & 3.0 & - & 3.0 & 2.8 & 2.7 & 2.6 & 2.4 \\
\hline \multicolumn{11}{|c|}{ Refrigerator/stale flavor $(\mathrm{LSD}=0.3$ ) } \\
\hline \multirow[t]{2}{*}{ Refrigerated } & Bulk & ND & ND & ND & ND & 1.0 & 1.8 & 2.1 & 2.2 & 2.3 \\
\hline & Sticks & ND & ND & 1.2 & 1.1 & 1.8 & 2.2 & 2.5 & - & - \\
\hline \multirow[t]{2}{*}{ Frozen } & Bulk & - & - & ND & - & ND & ND & ND & 1.0 & 1.2 \\
\hline & Sticks & - & - & ND & - & 0.5 & 0.5 & 0.5 & 1.5 & 1.8 \\
\hline
\end{tabular}

${ }^{1}$ Means that differ by more than the least significant difference (LSD) are different $(P<0.05)$.

${ }^{2}$ Flavor was scored on a 15 -point universal intensity scale where $0=$ absence of attribute and $15=$ highest possible intensity of attribute in any product. Butter volatile flavors generally fall between 0 and 4 on this scale. Salty taste was consistent over time and storage conditions $(P>0.05)$, intensity $=10.08 \pm 0.15$ and $9.10 \pm 0.06$ for bulk and stick butter, respectively.

${ }^{3} \mathrm{NS}=$ no difference between bulk and stick butter across storage time $(P>0.05)$

${ }^{4}$ Refrigerated timepoints for 21 and 24 mo are bulk butter only.

storage time and the first to use descriptive sensory analysis to document butter flavor and butter flavor changes across storage. Our sensory results are consistent with previous studies that used qualitative sensory analysis techniques (grading). Emmons et al. (1986) found that butter frozen at $-18^{\circ} \mathrm{C}$ for 12 mo had undergone lesser flavor changes (increases in oxidized, paper/ cardboard, and other sensory defects determined by graders) than butter stored at $5^{\circ} \mathrm{C}$ for $14 \mathrm{wk}$. Furthermore, all but one of the paper-based wrappers had more grading deductions than prints stored in polyethylenebased wrappers. Jebson et al. (1974) found that butter stored in $25-\mathrm{kg}$ blocks in boxes lined with parchment and stored at $-18^{\circ} \mathrm{C}$ and $4^{\circ} \mathrm{C}$ incurred storage flavors after $8 \mathrm{mo}$ and butter stored at $4^{\circ} \mathrm{C}$ exhibited a greater level of storage flavor than butter stored at $-18^{\circ} \mathrm{C}$. Tomlinson and Dixon (1977) found that bulk butter stored in 25 -kg blocks at $-15^{\circ} \mathrm{C}$ did not have any off-flavors after $34 \mathrm{wk}$, consistent with the results observed in this study.

\section{$O S I, P V$, and FFV}

The OSI value for butters was determined as the length of time before the onset of a rapid increase in the rate of oxidation induced by high temperatures and air sparged into the sample. This lag time was measured in hours. Greater values indicate greater oxidative stability, and a decrease in OSI with storage time is indicative of oxidation. Storage temperature and packaging interactions were observed $(P<0.05$, Table 4). Refrigerated butters had the largest decline in oxidative stability over the 18-mo period. Frozen samples exhibited a constant OSI from 6 to 24 mo. Unlike sensory changes observed in butter flavor, there was no clear trend as to whether bulk butter or quarters had a slower rate of oxidation with either refrigerated or frozen butters. Oxidative stability has not been widely applied to storage of butters and spreads. In a 10 -wk study done by Kristensen et al. (2000), no oxidative degradation was detected when a sweet cream spread

Table 3. Mean butter spreadability scores separated by time and storage temperature $(\mathrm{LSD}=0.5)^{1,2}$

\begin{tabular}{lccccccccc}
\hline & \multicolumn{10}{c}{ Time (mo) } \\
\cline { 2 - 11 } $\begin{array}{l}\text { Storage } \\
\text { temperature }\end{array}$ & 0 & 3 & 6 & 9 & 12 & 15 & 18 & 21 & 24 \\
\hline Refrigerated & 6.0 & 6.2 & 5.9 & 5.8 & 5.7 & 5.2 & 5.4 & - & - \\
Frozen & - & - & 5.8 & - & 5.9 & 5.3 & 5.3 & 5.3 & 5.4 \\
\hline
\end{tabular}

${ }^{1}$ Means that differ by more than the least significant difference (LSD) are different $(P<0.05)$.

${ }^{2}$ Spreadability was scored on a product-specific scale where $0=$ not at all spreadable and $10=$ extremely spreadable. There was no difference between bulk and stick butter $(P>0.05)$. 
Table 4. Oxidative stability index (hours) over 15 mo separated by time, storage temperature, and packaging $(\mathrm{LSD}=0.8)^{1}$

\begin{tabular}{llccccccccc}
\hline & & \multicolumn{10}{c}{ Time $(\mathrm{mo})$} \\
\cline { 3 - 11 } Temperature & Packaging & 0 & 3 & 6 & 9 & 12 & 15 & 18 & 21 & 24 \\
\hline Refrigerated & Bulk & 11 & 11 & 9.1 & 5.5 & 6.3 & 5.7 & 5.0 & - & - \\
& Sticks & 12 & 11 & 9.7 & 6.5 & 6.5 & 5.2 & 4.4 & - & - \\
Frozen & Bulk & - & - & 8.5 & - & 8.3 & 8.6 & 8 & 6.8 & 9.1 \\
& Sticks & - & - & 9.3 & - & 8.8 & 8.1 & 8.3 & 8.6 & 8.8 \\
\hline
\end{tabular}

${ }^{1}$ Means that differ by more than the least significant difference (LSD) are different $(P<0.05)$.

was stored at $-18^{\circ} \mathrm{C}$ and $5^{\circ} \mathrm{C}$ using a similar oxidative stability method. This is comparable to the 3 -mo results observed in this study.

Peroxide value is a measure of the initial products of lipid oxidation. Differences in PV between storage temperature and time were significant $(P<0.05$; Figure 1). A large increase in PV was observed over the course of $18 \mathrm{mo}$ in both refrigerated and frozen storage, although it was greater in the refrigerated butter. Six months later, the PV of frozen butters increased significantly, whereas the PV of refrigerated butters did not show a significant increase. Evaluation of PV has been widely applied to butters with mixed results in relation to sensory perception of off-flavors. Emmons et al. (1986) found that PV was not elevated in butters that exhibited storage grading defects suggesting a different cause for stale off-flavors in butter. Similar to this study, Jebson et al. (1974) found an increase in PV occurred in bulk samples stored at $4^{\circ} \mathrm{C}$ after 4 and 8 mo. In contrast to this study, they found that butter stored at $-18^{\circ} \mathrm{C}$ yielded only a slight increase in PV after 8 mo. Okturk et al. (2001) found that butter stored at $5^{\circ} \mathrm{C}$ for $3 \mathrm{mo}$ had an almost 3 -fold increase in PV over this period. This result is consistent with the increase seen in this study between fresh butter and that stored for $6 \mathrm{mo}$ at $5^{\circ} \mathrm{C}$. Downey and Murphy (1968) found that when the PV was $>2 \mathrm{mEq}$ of peroxide/kg of fat, off-flavors were detected in butter by trained graders. In the current study, bulk butter was stored for 12 mo at $-20^{\circ} \mathrm{C}$ without any detection of off-flavors by the trained panel, despite the elevated PV. Abdel-Mageed and Fadel (1995) isolated volatile components from butter stored for $7.5 \mathrm{mo}$ at $-18^{\circ} \mathrm{C}$ and found that carbonyls caused by peroxidation of fatty acids were greatest after $4.5 \mathrm{mo}$ and decreased thereafter. This is in agreement with the PV decreases in this study after 6 mo of storage.

Free fatty acids are products of hydrolytic oxidation. The FFV in the butters increased with storage and were greater in refrigerated samples than in their frozen

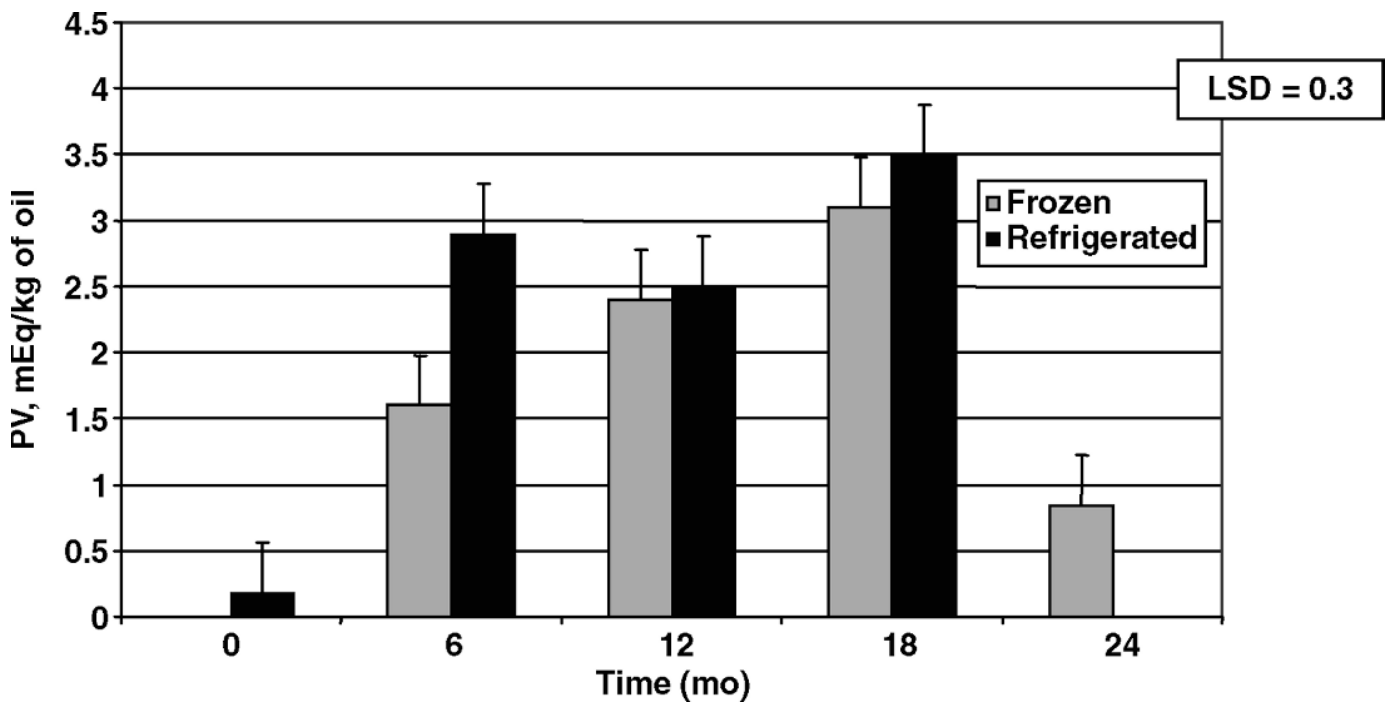

Figure 1. Peroxide value (PV) measured by AOCS method 965.33 (Chen et al., 2004) separated by storage temperature and time. Results are given in milliequivalents of peroxide/ $\mathrm{kg}$ of oil. Bars represent standard deviations of the means. Means that differ by more than the least significant difference are different $(P<0.05)$. There was no difference between bulk and stick butters $(P>0.05)$. 


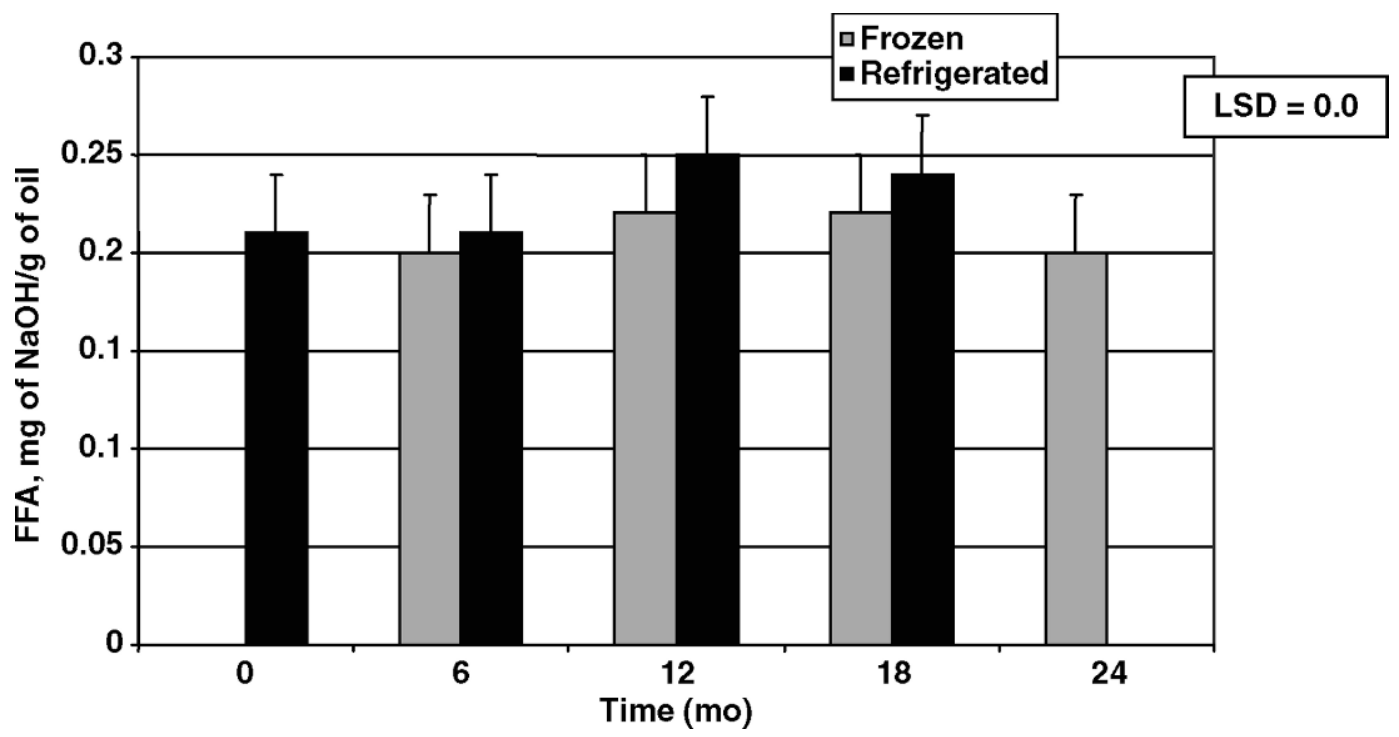

Figure 2. Free fatty acids measured as milligrams of $\mathrm{NaOH} / \mathrm{g}$ of butter oil separated by storage temperature and time. Bars represent standard deviations of the means. Means that differ by more than the least significant difference are different $(P<0.05)$. There was no difference between bulk and stick butters $(P>0.05)$.

counterparts $(P<0.05$; Figure 2). Although the difference in FFV between bulk $(0.21 \pm 0.002)$ and stick butter $(0.22 \pm 0.003, \mathrm{LSD}=0.009)$ was statistically significant $(P<0.05)$, the actual difference was very small and likely not of practical value or significance. O'Connell et al. (1975) found that the FFV of butter quarters and bulk butter did not increase over 56 wk of storage at $-18^{\circ} \mathrm{C}$. Similarly in this study, levels of FFA in butters were consistent through $6 \mathrm{mo}$ of storage before a slight increase was detected. Conversely, Okturk et al. (2001) found that FFV levels increased significantly over 90 $\mathrm{d}$ of storage at $5^{\circ} \mathrm{C}$.

The decrease in OSI was the most closely related instrumental measurement to the sensory perception of off-flavors in butter during refrigerated storage $(\mathrm{r}=$ $-0.91,0.63$, and 0.40 , respectively, for OSI, PV, and FFV). Decreases in OSI were concurrent with increases in perception of refrigerator/stale flavor. However, there was not a relationship between OSI, PV, or FFV and sensory perception across frozen storage $(r=-0.33$, 0.53 , and 0.46 , respectively). The sensory results of this study indicated that the development of refrigerator/ stale flavor was more rapid in butter quarters than in butter stored in bulk, and instrumental measurements did not show this differentiation. Previous studies have also proposed that lipid oxidation was not entirely responsible for the loss of flavor quality in butter (Pont, 1961; MacBean, 1974; Emmons et al., 1986). These results were further confirmed by Lozano et al. (2007), who demonstrated that styrene derivatives absorbed from packaging or storage were contributors to loss of fresh flavor in butter along with evolution of lipid oxidation compounds.

\section{Vane Rheometry}

Differences in yield stress $(\mathrm{Pa})$ were significant between storage temperatures and between packaging types $(P<0.05$; Figure 3$)$. Significant changes occurred in butters between 0 and 6 mo under both refrigerated and frozen storage conditions. At $12 \mathrm{mo}$, neither treatment was significantly different from the 6-mo value. When comparing packaging types, bulk butter had a significantly lower yield stress compared with butter in wax paper-wrapped sticks. Bulk butter had a yield stress of $5,787 \mathrm{~Pa} \pm 114$ across storage time, whereas stick butter had an average yield stress of 6,506 \pm 104 over $12 \mathrm{mo}$ (LSD = $246 \mathrm{~Pa} ; P<0.05$ ).

As refrigeration time increased, yield stress increased and yield strain decreased, indicating that the refrigerated butter took less rotation to fracture but more force. Daubert et al. (1998) found this direction of change to be a decrease in the spreadability of the product in the direction of a more brittle product. This decrease in spreadability of refrigerated butters is in agreement with the sensory results from this study. Kawanari et al. (1981) found that butter stored for 12 wk at $5^{\circ} \mathrm{C}$ was harder than butter stored at $-30^{\circ} \mathrm{C}$ for the same period. Kulkarni and Ramamurthy (1985) also explained temperature/storage effects on butter texture as attributable to the changes in the solidification of triglycerides during storage. 


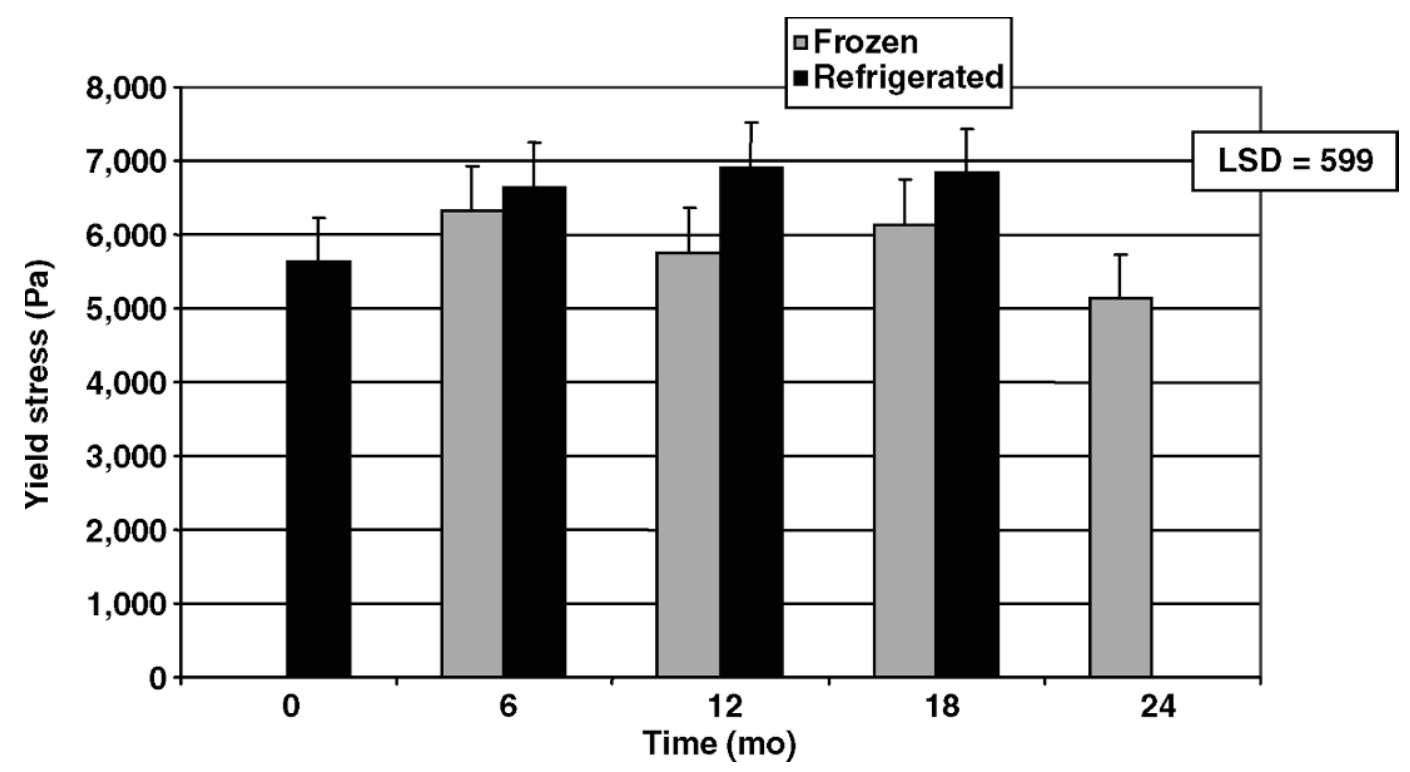

Figure 3. Yield stress $(\mathrm{Pa})$ measured using the vane method separated by storage temperature and time. Means that differ by more than the least significant difference are different $(P<0.05)$. Yield stress was measured at $19^{\circ} \mathrm{C}$; the vane had a diameter of $1.0 \mathrm{~cm}$ and a height of $2.5 \mathrm{~cm}$; the rotational speed of vane was $0.02 \mathrm{rpm}$. Bars represent standard deviations of the means.

\section{Instrumental Color of Solid Butter and Butter Oil}

Hunter $L^{*} a^{*} b^{*}$ values were measured to examine any color changes that occurred over storage time with solid butter and butter oil. Differences in the $\mathrm{L}^{*}$ value (where $100=$ white and $0=$ black) between bulk and stick butter were significant $(P<0.05)$. Stick butter was significantly lighter in color $(\mathrm{L}=78.5 \pm 0.13)$ than bulk butter $\left(\mathrm{L}^{*}=77.7 \pm 0.10, \mathrm{LSD}=0.3 ; P<0.05\right)$. Time and storage conditions also had a significant effect on $\mathrm{L}^{*}$ value (Table 5). Over time, the color of butter lightened when stored under both refrigerated and fro- zen storage conditions. The a* values were different based on packaging, storage condition, and time $(P<$ 0.05, Table 5). Bulk butter was more greenish (more negative $a^{*}$ value) than stick butter $(P<0.05)$. Although refrigerated and frozen storage were not significantly different from one another, the largest change in green color from the fresh samples occurred between 0 and 6 mo of storage.

The $b^{*}$ value indicates the degree of yellow or blue hue (positive values are yellow hues and negative values are blue hues). Although differences were present

Table 5. Instrumental color values ${ }^{1}$ for solid butter ${ }^{2}$

\begin{tabular}{|c|c|c|c|c|c|c|}
\hline \multirow[b]{2}{*}{ Storage temperature } & \multirow[b]{2}{*}{ Packaging } & \multicolumn{5}{|c|}{ Time (mo) } \\
\hline & & 0 & 6 & 12 & 18 & 24 \\
\hline \multicolumn{7}{|l|}{$\mathrm{L}^{*}(\mathrm{LSD}=0.51)$} \\
\hline Refrigerated & $\mathrm{NS}^{3}$ & 77.82 & 76.73 & 79.32 & 79.55 & 一 \\
\hline Frozen & NS & - & 76.62 & 79.74 & 79.07 & 79.53 \\
\hline \multicolumn{7}{|l|}{$\mathrm{a}^{*}(\mathrm{LSD}=0.14)$} \\
\hline \multirow[t]{2}{*}{ Refrigerated } & Bulk & -3.24 & -3.6 & -3.57 & -3.34 & - \\
\hline & Sticks & -3.02 & -3.5 & -3.46 & -3.17 & - \\
\hline \multirow[t]{2}{*}{ Frozen } & Bulk & - & -3.5 & -3.69 & -3.45 & -3.67 \\
\hline & Sticks & - & -3.46 & -3.41 & -3.28 & -3.38 \\
\hline \multicolumn{7}{|l|}{$\mathrm{b}^{*}(\mathrm{LSD}=0.40)$} \\
\hline \multirow[t]{2}{*}{ Refrigerated } & Bulk & 13.57 & 12.3 & 12.53 & 14.07 & - \\
\hline & Sticks & 13.28 & 12.38 & 13.71 & 13.55 & - \\
\hline \multirow[t]{2}{*}{ Frozen } & Bulk & - & 12.11 & 14.26 & 14.15 & 14.07 \\
\hline & Sticks & - & 12.17 & 13.97 & 14.22 & 13.89 \\
\hline
\end{tabular}

${ }^{1} \mathrm{~L}^{*}$ value on Hunter scale, where $100=$ white and $0=$ black.

${ }^{2}$ Means that differ by more than the least significant difference (LSD) are different $(P<0.05)$.

${ }^{3} \mathrm{NS}=$ no difference between bulk and stick butter across storage time $(P>0.05)$. 
Table 6. Instrumental color values ${ }^{1}$ for butter oil ${ }^{2}$

\begin{tabular}{|c|c|c|c|c|c|c|}
\hline \multirow[b]{2}{*}{ Storage temperature } & \multirow[b]{2}{*}{ Packaging } & \multicolumn{5}{|c|}{ Time (mo) } \\
\hline & & 0 & 6 & 12 & 18 & 24 \\
\hline \multicolumn{7}{|l|}{$\mathrm{L}^{*}(\mathrm{LSD}=0.32)$} \\
\hline \multirow[t]{2}{*}{ Refrigerated } & Bulk & 33.56 & 32.96 & 28.54 & 28.26 & - \\
\hline & Sticks & 33.59 & 33.72 & 28.48 & 28.27 & - \\
\hline \multirow[t]{2}{*}{ Frozen } & Bulk & - & 33.59 & 28.39 & 28.55 & 28.43 \\
\hline & Sticks & - & 33.66 & 28.45 & 28.52 & 28.53 \\
\hline \multicolumn{7}{|l|}{$\mathrm{a}^{*}(\mathrm{LSD}=0.08)$} \\
\hline Refrigerated & $\mathrm{NS}^{3}$ & 1.03 & -1.10 & -0.91 & -0.96 & - \\
\hline Frozen & NS & - & -1.10 & -1.01 & -0.83 & -0.84 \\
\hline \multicolumn{7}{|l|}{$\mathrm{b}^{*}(\mathrm{LSD}=0.20)$} \\
\hline Refrigerated & NS & 3.25 & 2.84 & 3.05 & 3.39 & - \\
\hline Frozen & NS & - & 2.80 & 3.56 & 2.80 & 3.06 \\
\hline
\end{tabular}

${ }^{1} \mathrm{~L}^{*}$ value on Hunter scale, where $100=$ white and $0=$ black.

${ }^{2}$ Means that differ by more than the least significant difference (LSD) are different $(P<0.05)$.

${ }^{3} \mathrm{NS}=$ no difference between bulk and stick butter across storage time $(P>0.05)$.

in the samples $(P<0.05)$, the trends were not clear. Statistical interactions between time and temperature and packaging are shown in Table 5. The frozen samples were consistently more yellow than the refrigerated samples after 12 mo of storage. There was no clear trend as to which packaging type had a higher $b^{*}$ value. Despite these instrumental differences, it is important to emphasize that there were no sensory-perceived visual differences between butters with storage.

A study of sweet cream dairy spreads by Kristensen et al. (2000) found that a very high storage temperature $\left(20^{\circ} \mathrm{C}\right)$ yielded darker butter (lower $\mathrm{L}^{*}$ values) after 10 wk of storage, and few differences were observed between samples kept at $-18^{\circ} \mathrm{C}$ and $5^{\circ} \mathrm{C}$ for the same time period. They also found that samples stored at $5^{\circ} \mathrm{C}$ were more green (lower $a^{*}$ values) and had higher $b^{*}$ values (were more yellow) compared with butters stored at $-18^{\circ} \mathrm{C}$.

Butter oil color was also evaluated because clarified melted butter is used widely in culinary applications. The degree of lightness of the oil, $\mathrm{L}^{*}$, decreased significantly after 18 mo of storage, and interactions were observed between storage temperature and packaging with storage time $(P<0.05$, Table 6$)$. Decreasing levels for $\mathrm{L}^{*}$ were observed in all samples across all packaging types, temperatures, and time. The green hue of the oil (a* value) was significantly different based on storage temperature and time (Table 6). Most notably, a reduction in green color of the refrigerated samples after 12 mo was observed. The yellowness of the oils $\left(b^{*}\right)$ changed with storage conditions and time (Table 6). A slight decrease in yellowness at 6 mo occurred under both storage conditions. This is consistent with observations in the solid butter color. Frozen butter had a higher level of yellow color than refrigerated butter. Although studies have examined butter oil and ghee stability over time and storage conditions (Kehagias and Radema, 1973), they have not examined color changes to our knowledge. Additionally, no studies have been conducted that examined changes in butter oil produced from stored butter.

\section{CONCLUSIONS}

There was a significant difference between bulk and stick butter in development of refrigerator/stale flavor and the reduction of cooked/nutty flavor. Observed changes in instrumental measures of lipid oxidation with storage were not entirely in agreement with sensory-perceived changes. Because development of stale flavors was not consistent with instrumental measurements of lipid oxidation, this is an indication that offflavor development in stored butter is coming at least in part from a source other than lipid oxidation.

Ideally, products should maintain quality and be free of perceived off-flavors throughout their shelf life. Refrigerated butter quarters showed the fastest decline in quality, and refrigerator/stale flavors were evident following $6 \mathrm{mo}$ at $5^{\circ} \mathrm{C}$. To this end, for optimum quality, butter quarters should be refrigerated for less than 6 mo. When frozen at $-20^{\circ} \mathrm{C}$, sticks can be stored for up to 12 mo. It is still advantageous for manufacturers to store butter in large blocks. Although it may not completely stop lipid oxidation and off-flavor development, it will maintain the flavors of freshly produced butter (milkfat, cooked/nutty flavors) longer. Our estimate of shelf life of bulk butter is conservative because 4-kg blocks were used for the study for convenience and cost, and butter is often stored in 25-kg block form. For bulk butter in refrigerated conditions, flavor quality is maintained for at least 9 mo. In frozen storage, bulk butter can be stored 18 mo without flavor detriment. 


\section{ACKNOWLEDGMENTS}

This study was funded in part by the California Dairy Research Foundation (Davis, CA). The authors wish to acknowledge the support of California Dairies Inc. (Visalia, CA) and the participation of the trained panelists. The use of trade names does not imply endorsement of those mentioned or lack of endorsement for those not mentions. Paper number FSR 07-32 of the Department of Food Science, North Carolina State University journal series.

\section{REFERENCES}

Abdel-Mageed, M., and H. Fadel. 1995. Effect of freeze storage on the volatiles of butter. Grasas y Aceites 46:165-168.

Bannon, C., J. Craske, N. Hai, N. Harper, and K. O’Rourke. 1982. Analysis of fatty acid methyl esters with high accuracy and reliability. II. Methylation of fats and oils with boron trifluoride-methanol. J. Chromatogr. 247:63-69.

Bradley, R. L., E. Arnold, D. M. Barbano, R. G. Semerad, D. E. Smith, and B. K. Vines. 1993. Chemical and physical methods. Pages 433-529 in Standard Methods for the Examination of Dairy Products. 16th ed. Am. Publ. Health Assoc. Inc., Washington, DC.

Breidinger, S., and J. Steffe. 2001. Texture map of cream cheese. J. Food Sci. 66:453-456.

Briggs, J., J. Steffe, and Z. Ustunol. 1996. Using the vane method to evaluate the yield stress of frozen ice cream. J. Dairy Sci. 79:527-531.

Chen, C., C. Dayton, J. Irudayaraj, and L. Sidisky. 2004. AOCS Official Method Cd 8-53. Peroxide value: Acetic acid-chloroform method. In Official Methods and Recommended Practices of the AOCS. 5th ed. D. Firestone, ed. Am. Oil Chem. Soc., Champaign, IL.

Daubert, C. R., J. Tkachuck, and V. D. Truong. 1998. Quantitative measurement of food spreadability using the vane method. J. Texture Stud. 29:427-435.

Downey, W., and M. Murphy. 1968. Light-barrier properties of various butter wrapping materials. J. Soc. Dairy Technol. 21:104-106.

Drake, M. A., S. C. McIngvale, K. R. Cadwallader, and G. V. Civille. 2001. Development of a descriptive language for Cheddar cheese. J. Food Sci. 66:1422-1427.

Emmons, D. B., D. A. Froehlich, G. J. Paquette, D. C. Beckett, H. W. Modler, G. Butler, P. Brackenridge, and G. Daniels. 1986. Flavor stability of butter prints during frozen and refrigerated storage. J. Dairy Sci. 69:2451-2457.
Dzuy, N., and D. Boger. 1983. Yield stress measurement for concentrated suspensions. J. Rheol. 27:321-349.

Fearon, A. M., and D. E. Johnston. 1989. A comparison of 3 instrumental techniques to evaluate butter spreadability. J. Food Qual. 12:23-38.

Jebson, R., A. McDowell, and R. W. Russell. 1974. The effect of storage temperature on the quality of salted sweet cream butter. N. Z. J. Dairy Sci. 9:163-165.

Kawanari, M., D. D. Hamann, K. R. Swartzel, and A. P. Hansen. 1981. Rheological and texture studies of butter. J. Texture Stud. 12:483-505.

Kehagias, C., and L. Radema. 1973. Storage of butter oil under various conditions. Neth. Milk Dairy J. 27:379-398.

Kornerup, A., and J. Wanscher. 1978 Methuen Handbook of Colour. E. Methuen, London UK.

Krause, A. J., K. Lopetcharat, and M. A. Drake. 2007. Identification of the characteristics that drive consumer liking of butter. J. Dairy Sci. 90:2091-2102.

Kristensen, D., M. Boesen, J. Jakobsen, L. Mansoon, L. Erichsen, and L. Skibsted. 2000. Oxidative stability of salted sour cream dairy spread compared to salted sweet cream dairy spread. Milchwissenschaft 55:504-507.

Kulkarni, S., and M. Ramamurthy. 1985. Studies on changes in rheological characteristics of butter stored at different temperature for different periods. Indian J. Dairy Sci. 38:111-114.

Lozano, P., R. E. Miracle, A. J. Krause, M. A. Drake, and K. R. Cadwallader. 2007. Effect of cold storage and packaging material on the major aroma components of sweet cream butter. J. Agric. Food Chem. 55:7840-7846.

MacBean, R. 1974. A comparison of butter wrapping materials. Aust. J. Dairy Technol. 29:25-28.

Meilgaard, M., G. V. Civille, and B. Carr. 1999. Descriptive analysis techniques. Pages 173-183 in Sensory Evaluation Techniques. M. Meilgaard, G. Civille, and B. Carr, ed. CRC Press, Boca Raton, FL.

Mortensen, B. K., and H. Danmark. 1982. Consistency characteristics of butter. Milchwissenschaft 37:530-532.

O'Connell, J., T. Cogan, and W. Downey. 1975. Lipolysis in butter pre and post-manufacture. Pages 92-100 in Proceedings of the Lipolysis Symposium, Cork, Ireland. Elsevier, London, UK.

Okturk, S., E. Sezgin, Z. Yildirim, and M. Yildirim. 2001. Effects of some technological processes and storage conditions on the contents of vitamins $\mathrm{A}$ and $\mathrm{E}$ in butter. Milchwissenschaft 56:667-669.

Pont, E. 1961. Surface deterioration of butter. Aust. J. Dairy Technol. 16:146-151.

Rohm, H., and F. Ulberth. 1989. Use of magnitude estimation in sensory texture analysis of butter. J. Texture Stud. 20:409-418.

Rousseau, D., and A. G. Marangoni. 1999. The effects of interesterification on physical and sensory attributes of butterfat and butterfat-canola oil spreads. Food Res. Int. 31:381-388.

Tomlinson, N., and B. D. Dixon. 1977. A comparison of wrapping materials for export butter. Aust. J. Dairy Technol. 32:70-71. 